\title{
Burden of Care and Psychological Distress in Primary Caregivers of Patients with Type -2 Diabetes Mellitus in A Tertiary Hospital in Nigeria
}

\author{
Ogunmodede Adebusola Jane ${ }^{1^{*}}$, Abiodun Olatunji ${ }^{2}$, Makanjuola Alfred \\ Bamiso $^{2}$, Olarinoye John Kola ${ }^{3}$, Ogunmodede James Ayodele ${ }^{3}$, Buhari \\ Olubunmi Ideraoluwa ${ }^{2}$
}

\section{OPEN ACCESS}

Citation: Ogunmodede Adebusola Jane, Abiodun Olatunji Alao, Makanjuola Alfred Bamiso, Olarinoye John Kola, Ogunmodede James Ayodele, Buhari Olubunmi Ideraoluwa Nimat. Burden of Care and Psychological Distress in Primary Caregivers of Patients with Type -2 Diabetes Mellitus in A Tertiary Hospital in Nigeria. Ethiop J Health Sci. 2019;29(6):697.doi:http://dx.doi.org/10.4 314/ejhs.v29 i6.6

Received: April 20, 2018

Accepted: July 22, 2019

Published: November 1, 2019

Copyright: (C2019 Ogunmodede

Adebusola Jane, et al. This is an open access article distributed under the terms of the Creative Commons Attribution License, which permits unrestricted use, distribution, and reproduction in any medium, provided the original author and source are credited.

Funding: None

Competing Interests: The authors declare that this manuscript was approved by all authors in its form and that no competing interest exists.

Affiliation and Correspondence:

${ }^{1}$ Department of Behavioural Sciences,

University of Ilorin Teaching Hospital,

Ilorin, Kwara State, Nigeria

${ }^{2}$ Department of Behavioural Sciences,

University of Ilorin, Ilorin, Kwara

State, Nigeria

${ }^{3}$ Department of Medicine, University of Ilorin Ilorin, Kwara State, Nigeria

*Email: busolajane@yahoo.com

\section{ABSTRACT}

BACKGROUND: Caregivers play an important role in the management and care of individuals with chronic medical conditions. This is because; they provide emotional, physical, financial as well as spiritual support to their wards. However, the process of caregiving is usually associated with feelings of burden and psychological distress.

METHODS: This study was a descriptive, cross-sectional, clinicbased study done at the endocrinology clinic of a Teaching hospital in Northern Nigeria. It was done utilizing the Zarit Burden Interview, the General Health Questionnaire (12 item version) and a socio-demographic questionnaire designed by the authors. The levels of burden as well as the factors associated with burden and psychological distress in one hundred caregivers of patients with Type 2 Diabetes Mellitus were assessed. Statistical analysis was done using chi square, independent $T$ test and linear regression.

RESULTS: Forty- two percent (42\%) of caregivers experienced little or no burden, 47\% had mild to moderate burden, $8 \%$ had moderate to severe burden, while 3\% had severe burden. When the ZBI scores were dichotomized into 'low' and 'high' burden, 89\% were found to experience low burden, while 11\% experienced high burden. On logistic regression, females were found to be four times more likely to experience high burden, while Thirty-five (35\%) percent of caregivers had a GHQ score of $\geq 3$, signifying psychological distress and psychological distress was found to be significantly associated with burden.

CONCLUSION: Many Nigerian caregivers of patients with Type 2 Diabetes Mellitus experience burden and psychological distress associated with caregiving, especially female caregivers and those taking care of those taking care of patients with complications. It is therefore important for clinicians to recognize burdened caregivers and intervene appropriately in order to improve the quality of care of these patients

KEYWORDS: Type 2 Diabetes Mellitus, caregiver burden, psychological distress. 


\section{INTRODUCTION}

The task of caring for relatives or wards with a chronic illness can be enormous and overwhelming. It is therefore often associated with both tangible and intangible costs to the caregivers called the caregiver burden (1). These costs include observable costs such as disruption in the caregiver's domestic routine and social activities, financial loss and loss of productive hours (2). It may also include the subjective feelings of distress, grief and worry which may be present in the caregiver (3). The concept of burden is known is recognized all over the world, $(4,5,6)$ In many low and middle income countries, where the bulk of payment for health care services is made out of pocket, patients and their caregivers bear the brunt of the financial responsibilities of medical care, contributing to financial burden (4). Thrush et al (5) reported that there is a considerable but neglected burden on caregivers in Low and Middle income countries in terms of financial, physical, psychological and time burden. Similar results were reported by Custodio et al (6) in Peru and Yakubu (7) in South Africa. In Nigeria, the situation is the same, with many caregivers bearing the burden of financial, emotional and physical obligations of care of the chronically ill. $(8,9)$

Psychological distress was defined by Mirowski and Ross (10) in 2002, as a state of emotional suffering characterized by symptoms of depression (such as lost interest, sadness and hopelessness) and anxiety (restlessness, feeling tense and somatic symptoms) that affects the individual's ability to cope with a particular set of circumstances. Psychological distress may have a bi-directional relationship with burden as it may account for part of the burden experienced by different caregivers or may in itself, be as a result of perceived burden associated with caring for a sick relative or ward (11).

Over the past few years, there has been a progression in the focus of research of patients with chronic mental or physical illnesses, from focusing not just on the patients alone, but also on their caregivers (12). This is because, caregivers of chronically-ill patients are now more recognized as playing a pivotal role in the recovery of their patients which ultimately, affect the clinical outcome of these patients (13).

Diabetes Mellitus (DM) is a chronic metabolic disorder with increasing prevalence worldwide, Nigeria inclusive (14) It was estimated by the World Health Organization, that about 1.7 million people were suffering from this illness in Nigeria in 2004 and this figure is expected to have tripled by year 2030 (15). Patients with this illness require regular drug use, regular clinic follow - up as well as lifestyle and dietary modifications, all of which may require the assistance of a caregiver. Of particular importance also, is the role of caregivers in assisting patients who suffer disability from complications of the illness such as blindness, limb amputation. Globally, and especially in Nigeria, most caregiver burden studies have been carried out in caregivers of patients with chronic mental disorders such as schizophrenia and bipolar affective disorders $(9,16$,$) , with few studies spotlighting the burden of$ care in chronic medical disorders such as Type 2 DM (17). Studies have revealed that caregivers of patients with Type 2 DM experience high burden and may sometimes experience significant psychological distress and can be prone to psychological disorders such as depression and anxiety (18). In spite of this, there is a serious dearth of studies on the burden of this illness on the caregivers of the affected.

This present study investigated the level of burden and psychological distress among caregivers of patients with Type $2 \mathrm{DM}$, determine the presence of psychological distress and factors associated with the burden of care. The study aimed at determining the level of burden in caregivers of Type $2 \mathrm{DM}$, patient and caregiver factors associated with burden as well as to determine the presence of psychological distress and its relationship to burden in these caregivers.

\section{MATERIALS AND METHODS}

This was a cross sectional clinic-based study, which was conducted between June and December 2016. This study was conducted at the outpatient Endocrinology clinic of the University of Ilorin Teaching Hospital (UITH), Ilorin, and Kwara State, Nigeria. Ilorin is an urban setting and serves

DOI: http://dx.doi.org/10.4314/ejhs.v29i6.6 
as the capital city of Kwara State, in the NorthCentral geopolitical zone of Nigeria (19).

Study population: Participants were caregivers of patients receiving treatment at the DM outpatient clinic of the hospital. This clinic receives an average of 768 patients per year (consisting of both old and new cases)

Inclusion and exclusion criteria for caregivers: Primary caregivers of Type $2 \mathrm{DM}$ patients who were aged 18 years and above and who had been caring for the patients for at least 6 months and who gave consent for participation. Primary caregivers with history of current or previous psychiatric illness, other severe or debilitating medical or surgical illness, or who took care of more than one chronically ill patient were excluded from the study.

Inclusion and exclusion criteria for patients: Adult Type $2 \mathrm{DM}$ patients aged 18 to 65years diagnosed according to the WHO criteria (10) who had had the illness for six months or more were recruited. Patients who had other co-morbid medical conditions were excluded from the study.

Procedure for the Study: Patients with a diagnosis of Type $2 \mathrm{DM}$ made by the consultant endocrinologist according to the WHO Criteria (20) who met the set inclusion criteria, were recruited for the study. They were recruited along with their primary caregivers. Pre-existing Yoruba (the predominant local language spoken by almost all respondents) versions of the Zarit burden scale and the 12 item GHQ were used, while the sociodemographic questionnaire was backtranslated by bilingual experts in conjunction with the researcher.

The operational definition of a primary caregiver in this study was an individual who was the principal person actively involved in the care of the patient and assisted the patient with either dayto-day task, ensuring compliance with medications, financial assistance with medical bills or regularly accompanying patient to the hospital.

Sample size calculation/ sampling technique: The estimated sample size of 67 was obtained using Fisher's formula for calculation of sample size (21), using a national prevalence rate of Type 2 DM of $4.6 \%$ (22) and a power of $90 \%$. However to improve the power and generalisability of the study, the sample size was increased to 100 , based on the fact that the statistical power of a study is improved by an increase in the sample size (23) and availability of willing participants. Participants were recruited by systematic random sampling, selecting every $4^{\text {th }}$ patient-caregiver dyad who met the inclusion criteria on every clinic day during the study period. The sampling interval was determined by the estimated number of 384 patients who attend the clinic in 6 months (sampling frame) divided by the estimated sample size of 100. Altogether, one hundred and five patient-caregiver dyads were approached, but five declined participation stating reasons such as time constraints and lack of interest in the study. Subsequently, a total of 100 patient- caregiver dyads were involved in the study after giving informed consent.

Data collection: The caregivers were required to complete a self-administered socio-demographic questionnaire, the 22 item Zarit Burden Interview (ZBI) and the 12 item version of the General Health Questionnaire (GHQ-12). Patients completed a socio-demographic questionnaire and pertinent information regarding the number of their hospitalizations, duration of illness and presence of complications were obtained from patients' medical records in conjunction with the consultant endocrinologists. Participants who could not read or write English were assisted to complete the questionnaires by reading out the questions and responses to them.

\section{Instruments:}

ZARIT BURDEN INTERVIEW: This is a 22 item instrument which is used for the assessment of the level of burden experienced by caregivers of patients with chronic illnesses (24). It explores the negative mental, physical, social and economic impacts of caregiving on the lives of caregivers (25). This instrument is regarded as one of the most commonly used instruments for burden assessment worldwide and has been used severally in the assessment of burden in such chronic illnesses such as Schizophrenia (26). It is scored using a five-point Likert scale with responses ranging from 0 (never), to 4 (nearly always) and scores caregivers on a total score of 88 (27). For 
the purpose of this study, the ZBI scores were further dichotomized into low burden (0-40) and high burden (41-88) as done in previous similar studies $(8,27)$.

GENERAL HEALTH QUESTIONNAIRE: This instrument was designed by Goldberg in 1972 in England as a self-administered questionnaire to screen for psychiatric morbidity in the community and in non-psychiatric clinical settings and has many versions (28). The GHQ-12 has been found to be useful in measuring psychological distress in designated populations (29). This instrument has been validated for use in Nigeria by Abiodun, who recommended a cut-off of 3 for determining probable psychiatric morbidity (30). The binary system of scoring was used in this study. The GHQ was used as a measure of psychological distress resulting from caregiving duties, and a score of $\geq 3$ adopted as indicating significant psychological distress

Data Analysis: The Data generated from this study was analyzed using the Statistical Package for Social Sciences (SPSS version 20). Descriptive statistics were used to summarize the data. Continuous variables were expressed as mean + standard deviation, while frequencies of categorical variables were expressed as percentages. The chi square and were used to analyze categorical and continuous variables. Logistic regression was then used to identify predictors of burden of care. The significance level was set at $\mathrm{p}<0.05$.

Ethical approval: An Ethical approval for the study was obtained from the Ethics and Research Committee of the University of Ilorin Teaching Hospital. The research was done according to the principles of the Helsinki declaration (31).

\section{RESULTS}

A total of 105 patient-caregiver pairs that satisfied the study criteria were approached during the period of the study. Five opted out of the study stating reasons of time constraints and lack of interest in the study. The participation rate was $95.3 \%$.

The mean age of caregivers was $46.5 \pm 14.5$ years. There were more female caregivers $(56 \%)$ than males. Most caregivers were married (77\%), had a tertiary level of education $(68 \%)$ and majority were children and spouses of the patients (74\%) (Table 1).

Table 1: Sociodemographic Characteristics of caregivers of patients with Type- 2 diabetes mellitus.

\begin{tabular}{|c|c|}
\hline Variables & n (\%) \\
\hline \multicolumn{2}{|l|}{ Age group } \\
\hline$\leq 20$ & $6(6.0)$ \\
\hline $21-40$ & $27(27.0)$ \\
\hline $41-60$ & $52(52.0)$ \\
\hline$>60$ & $15(15.0)$ \\
\hline Mean Age \pm SD & $46.46 \pm 14.48$ \\
\hline \multicolumn{2}{|l|}{ Gender } \\
\hline Male & $44(44.0)$ \\
\hline Female & $56(56.0)$ \\
\hline \multicolumn{2}{|l|}{ Marital status } \\
\hline Single & $21(21.0)$ \\
\hline Married & $77(77.0)$ \\
\hline Widowed & $2(2.0)$ \\
\hline \multicolumn{2}{|l|}{ Religion } \\
\hline Christianity & $51(51.0)$ \\
\hline Islam & $49(49.0)$ \\
\hline \multicolumn{2}{|c|}{ Educational qualification } \\
\hline No formal & $5(5.0)$ \\
\hline Primary & $10(10.0)$ \\
\hline Secondary & $17(17.0)$ \\
\hline Tertiary & $68(68.0)$ \\
\hline \multicolumn{2}{|c|}{ Employment status } \\
\hline Employed & $66(66.0)$ \\
\hline Unemployed & $34(34.0)$ \\
\hline \multicolumn{2}{|c|}{ Relationship to patient } \\
\hline Parents & $10(10.0)$ \\
\hline Child & $40(40.0)$ \\
\hline Spouse & $34(34.0)$ \\
\hline Siblings & $11(11.0)$ \\
\hline Unrelated & $1(1.0)$ \\
\hline Others & $4(4.0)$ \\
\hline
\end{tabular}

The mean duration of caregiving by the caregivers was $6.7 \pm 5.8$ years. Almost all caregivers $(99 \%)$ were not paid for their duties. Most caregivers $(78 \%)$ had support from other secondary caregivers, were seeing their patients every day $(83 \%)$ and travelled more than $15 \mathrm{~km}$ to get to the 
hospital (66\%). About $66 \%$ of caregivers cumulatively rated their general physical health as good or excellent (Table 2).

Table 2. Caregiving Characteristics of care givers of Type-2 diabetes mellitus.

\begin{tabular}{ll}
\hline Variable & n (\%) \\
\hline Duration of Caregiving (Years) & \\
$<5$ & $60(60.0)$ \\
$6-10$ & $26(26.0)$ \\
$>10$ & $14(14.0)$ \\
Mean (SD) & $6.6(5.80)$ \\
Lone caregiver & \\
Yes & $22(22.0)$ \\
No & $78(78.0)$ \\
Paid for caregiving & $1(1.0)$ \\
Yes & $99(99.0)$ \\
No & \\
Residing with patient & $67(67.0)$ \\
Yes & $33(33.0)$ \\
No & \\
Frequency of contact with patient & $83(83.9)$ \\
Daily & $10(10.0)$ \\
Weekly & $5(5.0)$ \\
2 to 3 times a month & $2(2.0)$ \\
Several times a year & \\
Number of hours of contact with & \\
$\leq 5$ & $12(14.5)$ \\
$6-10$ & $18(21.7)$ \\
$11-15$ & $22(26.5)$ \\
$>16$ & $31(37.3)$ \\
Distance travelled to Hospital $(\mathbf{k m})$ & \\
$\leq 5$ & $4(4.0)$ \\
$6-10$ & $6(6.0)$ \\
$11-15$ & $24(24.0)$ \\
$>15$ & $66(66.0)$ \\
Rating of caregiver's general & \\
physical health & \\
Excellent & $21(21.0)$ \\
Good & $45(45.0)$ \\
Fair & $33(33.0)$ \\
Poor & $1(1.0)$ \\
\hline
\end{tabular}

Table 3: Sociodemographic and Illness Characteristics of caregivers of patients with Type-2 diabetes mellitus.

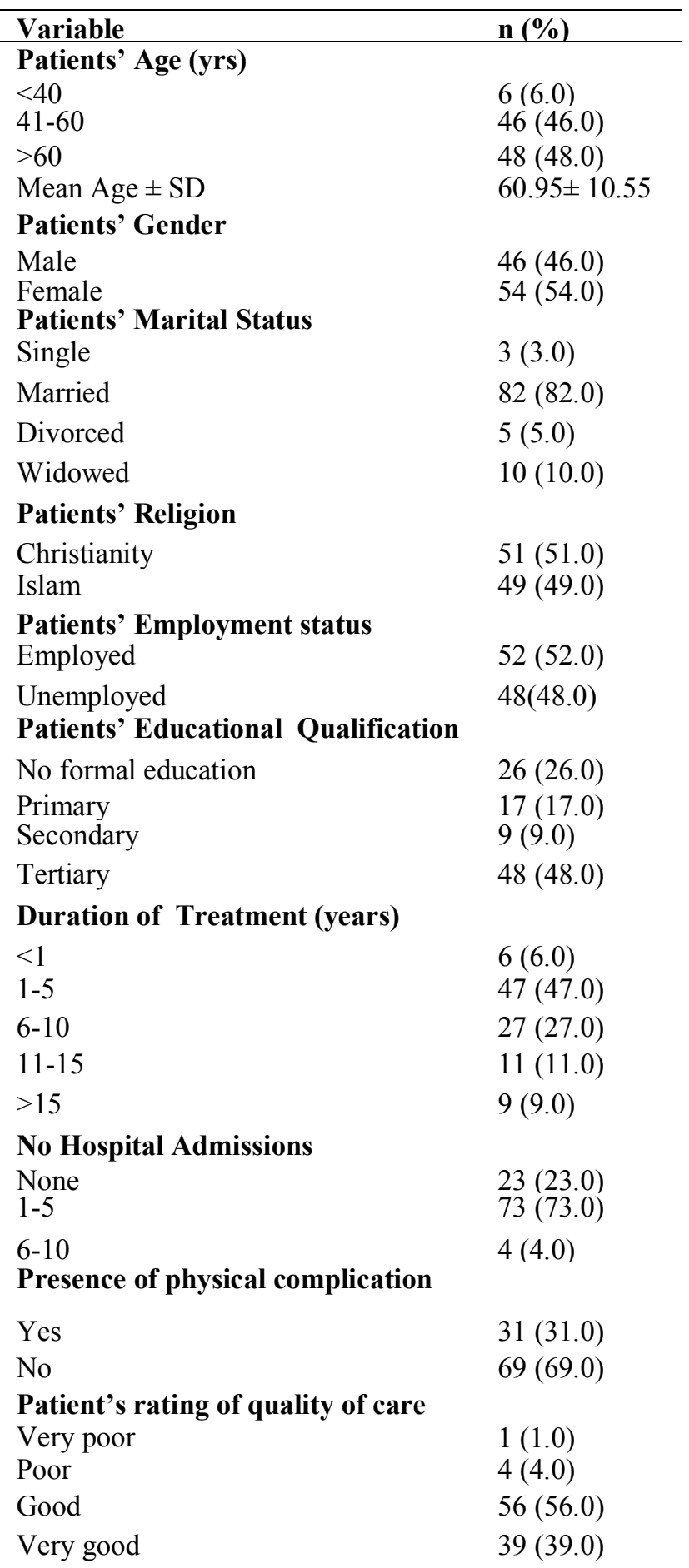

DOI: http://dx.doi.org/10.4314/ejhs.v29i6.6 
The mean age of patients was $60.9 \pm 10.6$. There were more female patients than males $(56 \%)$ and majority of the patients were married $(82 \%)$. About $52 \%$ were employed. The mean duration of treatment was $6.7 \pm 5.8$ years. Majority of the patients $(73 \%)$ had been admitted in the hospital between 1 and 5 times since the onset of their illness and $31 \%$ reported the presence of physical complications such as diabetic foot syndrome, diabetes- related eye diseases, peripheral neuropathy and erectile dysfunction. Most patients $(95 \%)$ rated the quality of care received from their caregivers as good and very good. (Table 3 ).

Table 4: Zarit Burden Interview Scores In Caregivers Of Patients With Type 2 Diabetes Mellitus

\begin{tabular}{ll}
\hline Variable & DM n (\%) \\
\hline Zarit Burden Interview(ZBI) Score & \\
Mean ZBI Score & $25.5 \pm 13.8$ \\
Interpretation of score & $42(42.0)$ \\
0-20 ( Little or no burden ) & $47(47.0)$ \\
21-40 (Mild to Moderate burden) & $8(8.0)$ \\
$41-60$ ( Moderate to severe burden) & $3(3.0)$ \\
61-88 ( Severe burden) & \\
Dichotomized Grading of ZBI Scores & $89(89.0)$ \\
Low Burden (ZBI 0-40) & $11(11.0)$ \\
High Burden (ZBI 41-88) & \\
\hline
\end{tabular}

Burden of care in caregivers: The mean ZBI score was $25.5 \pm 13.8$. Forty- two percent $(42 \%)$ of caregivers experienced little or no burden, $47 \%$ had mild to moderate burden, $8 \%$ had moderate to severe burden, while three percent had severe burden. When the ZBI scores were dichotomized into 'low' and 'high' burden, $89 \%$ were found to experience low burden, while $11 \%$ experienced high burden. Factors significantly associated with caregiver burden on bivariate analysis were the gender of the caregiver $\left(x^{2}=7.808, \mathrm{p}=0.005\right)$, GHQ-12 scores of caregivers $\left(x^{2}=7.436, \mathrm{p}=0.006\right)$ and the presence of physical complications of the illness in the patient $\left(x^{2}=\right.$ $45.068, \mathrm{p}<0.001)$ (Table 5).

Table 5: Caregiver and Patient Factors and Their Relationship with Burden of Care

\begin{tabular}{|c|c|c|c|c|}
\hline Variables & $\begin{array}{l}\text { Low burden } \\
\text { n (\%) }\end{array}$ & $\begin{array}{l}\text { High burden } \\
\text { n (\%) }\end{array}$ & $\chi^{2}$ & $p$ value \\
\hline \multicolumn{5}{|l|}{ Age of Caregiver } \\
\hline$\leq 20$ & $5(83.3)$ & $1(16.7)$ & 0.152 & 0.985 \\
\hline $21-40$ & 24(88.9) & $3(11.1)$ & & \\
\hline $41-60$ & $46(88.5)$ & $6(11.5)$ & & \\
\hline$>60$ & $14(93.3)$ & $1(6.7)$ & & \\
\hline \multicolumn{5}{|l|}{ Gender } \\
\hline Male & $44(100.0)$ & $0(0.0)$ & $7.808^{\mathrm{Y}}$ & $0.005 *$ \\
\hline Female & $45(80.4)$ & $11(19.6)$ & & \\
\hline \multicolumn{5}{|l|}{ Marital status } \\
\hline Single & $18(85.7)$ & $3(14.3)$ & 0.508 & 0.776 \\
\hline Married & $69(89.6)$ & $8(10.4)$ & & \\
\hline Divorced/Separated/Widowed & $2(100.0)$ & $0(0.0)$ & & \\
\hline \multicolumn{5}{|l|}{ Tribe } \\
\hline Yoruba & $76(70.5)$ & $11(29.5)$ & $0.21^{\mathrm{Y}}$ & 0.976 \\
\hline Hausa & $5(100.0)$ & $0(0.0)$ & & \\
\hline Igbo & $5(100.0)$ & $0(0.0)$ & & \\
\hline Others & $3(100.0)$ & $0(0.0)$ & & \\
\hline
\end{tabular}

DOI: http://dx.doi.org/10.4314/ejhs.v29i6.6 
Table 5. Continued...

\begin{tabular}{|c|c|c|c|c|}
\hline \multicolumn{5}{|l|}{ Religion } \\
\hline Christianity & $47(92.2)$ & $4(7.8)$ & 1.060 & 0.303 \\
\hline Islam & $42(85.7)$ & $7(14.3)$ & & \\
\hline \multicolumn{5}{|l|}{ Occupation } \\
\hline Employed & $57(86.4)$ & $9(13.6)$ & $0.405^{\mathrm{Y}}$ & 0.939 \\
\hline Unemployed & $4(100.0)$ & $0(0.0)$ & & \\
\hline Students & $11(91.7)$ & $1(8.3)$ & & \\
\hline Retired & $17(94.4)$ & $1(5.6)$ & & \\
\hline \multicolumn{5}{|l|}{ Educational status } \\
\hline No formal Education & $4(80.0)$ & $1(20.0)$ & $0.611^{\mathrm{Y}}$ & 0.893 \\
\hline Primary & $10(100.0)$ & $0(0.0)$ & & \\
\hline Secondary & $16(94.1)$ & $1(5.9)$ & & \\
\hline Tertiary & $59(86.8)$ & $9(13.2)$ & & \\
\hline \multicolumn{5}{|c|}{ Distance Travelled to Hospital } \\
\hline$<5-15 \mathrm{~km}$ & $30(100.0)$ & $2(0)$ & $0.488^{\mathrm{Y}}$ & 0.485 \\
\hline$>15 \mathrm{~km}$ & $59(86.8)$ & $9(13.2)$ & & \\
\hline \multicolumn{5}{|l|}{ Relationship to patient } \\
\hline Parents & $9(90.0)$ & $1(10.0)$ & $4.690^{\mathrm{Y}}$ & 0.454 \\
\hline Child & $37(92.5)$ & $3(7.5)$ & & \\
\hline Spouse & $27(79.4)$ & $7(20.6)$ & & \\
\hline Unrelated caregiver & $1(100.0)$ & $0(0.0)$ & & \\
\hline Other Relatives & $15(100.0)$ & $0(0.0)$ & & \\
\hline \multicolumn{5}{|l|}{ GHQ } \\
\hline$<3$ & $65(95.6)$ & $3(4.4)$ & 7.436 & $0.006 *$ \\
\hline$\geq 3$ & $24(75)$ & $8(25)$ & & \\
\hline \multicolumn{5}{|c|}{ Presence of physical complications } \\
\hline Yes & $7(22.6)$ & 1 & 45.068 & $<0.001 *$ \\
\hline No & $62(89.9)$ & & & \\
\hline \multicolumn{5}{|c|}{ Duration of Treatment (years) } \\
\hline$<1$ & $6(100.0)$ & 4 & $0.501^{\mathrm{Y}}$ & 0.973 \\
\hline $1-5$ & $42(89.4)$ & & & \\
\hline $6-10$ & $24(88.9)$ & & & \\
\hline $11-15$ & $9(81.8)$ & & & \\
\hline$>15$ & $8(88.9)$ & & & \\
\hline \multicolumn{5}{|c|}{ Number Hospital Admissions } \\
\hline None & $21(91.3)$ & 2 & $0.041^{\mathrm{Y}}$ & 0.979 \\
\hline $1-5$ & $65(89.0)$ & & & \\
\hline $6-10$ & $3(75.0)$ & & & \\
\hline \multicolumn{5}{|c|}{ Patients' Rating of quality of care } \\
\hline Very poor & $1(100.0)$ & 3 & $3.401^{\mathrm{Y}}$ & 0.333 \\
\hline Poor & $4(100.0)$ & & & \\
\hline Good & $47(83.9)$ & & & \\
\hline Very good & $37(94.9)$ & & & \\
\hline
\end{tabular}

$\chi^{2}$ : Chi square test; df: degree of freedom; Y: Yates corrected chi square; *: $p$ value $<0.05$

DOI: http://dx.doi.org/10.4314/ejhs.v29i6.6 
A binary logistic regression was performed to ascertain the independent predictors of high burden among the Caregivers of Type 2 DM patients. Variables that showed a significant association with burden of care were inputed in to the regression model. The 'the outcome variable was burden of care and it was dichotomised into low burden (coded as 0 ) and high burden (coded as 1). (21, 22). The logistic regression model showed good fit (Hosmer and Lemeshow test $p=$ 0.887 , chi square $=5.466$, df $=3, p=0.023$ ). The factors that independently predicted a high burden of care were- female sex of the caregiver $(\mathrm{OR}=4.049, \mathrm{CI}: 1.533-10.693)$ and the presence of physical complications in the patient $(\mathrm{OR}=1.547$, CI:1.176 -4.158).

The results indicate that female caregivers had a four-fold likelihood of reporting a high burden of care compared to male caregivers. Also, caregivers of Type 2 DM patients who had complications of disease were about one and a half times more likely to report a high burden of care compared with caregivers whose patients had no physical complications

Table 6: Predictors of Burden of care in caregivers of Type 2 Diabetes mellitus

\begin{tabular}{lccccc}
\hline Variable & B & $\boldsymbol{p}$ value & OR & \multicolumn{2}{c}{$\mathbf{9 5 \%}$ CI } \\
& & & & Lower & Upper \\
\hline Gender of the caregiver & 1.398 & $\mathbf{0 . 0 0 5}^{*}$ & 4.049 & 1.533 & 10.693 \\
$\begin{array}{l}\text { Presence of Physical complications in } \\
\text { patient }\end{array}$ & 0.436 & $\mathbf{0 . 0 3 9 *}$ & 1.547 & 1.176 & 4.158 \\
GHQ-12 Score & -0.691 & 0.152 & 0.501 & 0.195 & 1.288
\end{tabular}

B: Regression coefficient, OR- Odds Ratio, Sex: Male- 0, Female- 1, Presence of physical complications- No physical complication- 0, Presence of physical complications- 1, GHQ-12 Score: GHQ Score $<3-0$, GHQ Score $\geq 3-1 .{ }^{*} p<0.05$

Psychological distress in caregivers: The psychological distress experienced by caregivers was assessed using the GHQ-12, with a score of three and above indicating psychological distress. Sixty-five (65\%) caregivers experienced had GHQ score of $<3$, while $35(35 \%)$ caregivers had scores $\geq 3$, signifying psychological distress (Fig 2). Among caregivers of patients with Type 2 DM who had GHQ scores of $\leq 3,65(95.6 \%)$ experienced low burden, while only three (4.4\%) had a high burden. Among those with GHQ scores of $\geq 3$, (i.e. those who experienced psychological distress), 24 (75\%) had low burden, while eight (25\%) experienced high burden. This association between burden of care and psychological distress was statistically significant. $\left(x^{2}=7.436, \mathrm{p}=0.006\right)$. Although the presence of psychological distress was found to be significantly associated with the burden of care experienced by caregivers in this study, it was not predictive of the experiencing a high burden.

\section{DISCUSSION}

This study found a larger proportion of caregivers to be females; this is consistent with findings from earlier caregiver studies done in Nigeria and other parts of the world $(8,32,33)$ which also observed a preponderance of females as caregivers of patients with chronic physical illnesses. This may be linked to the predominant cultural perception in Nigeria and other parts of the world of women as natural caregivers, a role believed to be endowed on them by their natural function in the family (34). Most caregivers in this study were employed, and this has been reported as well by Anaforoglu et al (35). This is probably because employed relatives may have the financial wherewithal to cater for the needs of their sick relatives, especially as regards treatment costs and therefore may find it easier to take up caregiving duties.

A significant proportion of caregivers in this study were also found to consist of children and spouses of the patient. This is not surprising because in the Nigerian society, most of the patients sampled being middle aged and elderly would most likely be married and have children, who would assume the role of natural caregivers in the event of a

DOI: http://dx.doi.org/10.4314/ejhs.v29i6.6 
chronic illness. This finding is also reflective of the strength of family relationships in our society and underscores the importance of first degree relatives in the care of patients with a chronic physical illness such as Type $2 \mathrm{DM}$.

The levels of burden in this study refer to the ranking of the impacts of the caregiving responsibility on the caregiver's life, physically, psychologically, financially and socially amongst others. This study found that it was burdensome taking care of a patient with Type 2 DM, with all caregiver participants experiencing varying degrees of burden depending on the various sociodemographic and clinical factors. More than half of the caregivers in this study experienced between mild to severe levels of burden, with more than ten percent admitting to severe levels of burden. This shows that not only chronic psychological illnesses can cause strain to the caregivers, but a chronic physical illness such as Type 2 DM. This trend has been reported in similar studies (13).

Being a female was found to be associated with a four times higher likelihood of experiencing high burden compared to male caregivers. Impett and Peplau (36) described a possible explanation for this when they opined that female caregivers were more likely than males to put other people's needs above theirs and so are more dedicated to caring for their physically ill relatives. They would however in the process of caring, most likely have to juggle caregiving duties with house chores, child-care and other domestic responsibilities. All of these would expectedly contribute to the higher levels of burden experienced by female caregivers.

Caregivers of patients with complications of Type 2 DM were also found in this study to be one and half times more likely to experience high levels of burden than those caring for Type 2 DM patients with no physical complications. This finding is similar to observations by Nabuurs-Franssen et al and Langa et al $(32,37)$. This is probably due to the fact that as the number of DM complications increased, there was an increase in the complexity of care expected to be given by the patient's caregiver thereby imposing a serious burden on him/her (37). Some complications of Type 2 DM such as Diabetes associated eye diseases and blindness or limb amputation from neuropathy are associated with functional disabilities and restrictions in performing some basic and complex activities of daily living. This causes a partial or total dependency on the caregivers, who therefore experience more burden. This is particularly of significance in a resource-limited country like Nigeria where good quality living aids for physically disabled persons are either unavailable or very expensive with payments made mostly out of pocket (22).

Psychological distress was found to be significantly associated with the level of burden experienced by caregivers in this study. Though there are very few studies that have examined this relationship in caregivers of Type 2 DM patients, it is not surprising that feelings of frustration and being overwhelmed or overly- anxious which describes the state of being psychologically distressed is found to be significantly associated with the level of burden experienced by the caregiver. This is possibly linked to the fact that caregivers who experience significantly high burden of levels may consequently find it very difficult coping with the demands of caregiving and consequently feel distressed psychologically. The finding of a relationship between burden and psychological distress is of importance in clinical practice as psychological distress is regarded as a marker of a risk of a psychiatric morbidity in that caregiver, negatively impacting on the quality of care the caregiver is able to offer and subsequently on the clinical outcome of the patients.

In conclusion, caregivers of patients with Type 2 DM experience varying degrees of burden and psychological distress consequent upon caregiving duties. Awareness of determinants of burden will assist in early detection of burdened caregivers and hopefully stimulate practical interventions to reduce burden as well as provide a substrate for the formulation of helpful policies to mitigate caregiver distress and burden.

The limitations of this study were that both paid and unpaid caregivers were recruited for this study, and monetary gain may have altered the perception of burden in those caregivers who were paid. Also, this study was a cross sectional study 
and therefore was not able to establish the direction of causality.

\section{ACKNOWLEDGMENTS}

The authors acknowledge the Dr Sunmolu Adio and $\mathrm{Dr}$ Adeoye for their assistance in data collection.

\section{REFERENCES}

1. Dilehay RC, Sandy SM. Caregivers of patients with alzeimers, what are we learning from research. International Journal of Ageing and Human Development 1990;30(4): 263-85.

2. Lasebikan VO, Ayinde OO. Family burden in caregivers of schizophrenic patients: prevalence and sociodemographic correlates. Indian Journal Psychological Medicine 2013;35(1):60-6.

3. Medalie J. The caregiver as hidden patient: The theory and research on health care triads. Journal Health and Social Behaviour 1994;35:1-12.

4. Gureje O. Psychiatry in Africa, The myths, the exotic and the realities. African Journal Psych 2007;10:11-4.

5. Thrush A, Hyder AA. The neglected burden of caregiving in low and middle income countries. Disability Health Journal, 2014;7(3):262-726.

6. Custodio N, Liva D, Herrera-Perez E, Nurlezdel Prado L, Parodi J, Silva E et al. Informal Caregiver burden in Middle-Income Countries: Results from memory centres in Lima-Peru. Cement. Neuropsychol, 2014:8(4). 376-383.

7. Yakubu YA, Schutter DW. Caregiver attributes and Sociodemographic determinants of caregiving burden in selected low income communities in Cape Town, South Africa . Journal of Compassionate Health Care. 2018;5:3.
8. Oche M. Psychosocial impact of caring on caregivers of patients with chronic illness. (Fellowship Dissertation) Lagos: West African Postgraduate Medical College; 2010.

9. Yusuf AJ, Nuhu FT, Akinbiyi A. Caregiver burden among relatives of patients with schizophrenia in Kastina, Nigeria. South African Journal of Psychiatry, 2009;15(2):43.

10. Mirowsky J, Ross CE. Selecting Outcomes for the Sociology of Mental Health. Issues of measurement and dimensionality. Journal of health and social behavior, 2002; 43(1):152170.

11. Agbaminoja AJ. The burden of care: comparison between carers of patients with bipolar disorder and those with schizophrenia. (Fellowship dissertation) Lagos: West African Postgraduate Medical College; 2012.

12. Viana MC, Gruber MJ, Shahly V, Alhamzawi A, Alonso J, Andrade LH, et al. Family burden related to mental and physical disorders in the world. Results from the WHO World Mental Health (WMH) surveys. Revista Brasillerra de Psiquiatria, 1999;35(1):115-25.

13. Ampalam P, Gunturu S, Padma V. A comparative study of caregiver burden in psychiatric illness and chronic medical illness. Indian Journal of Psychiatry, 2012;54(3):23943.

14. Olokoba AB, Obateru OA, Olokoba LB. Type 2 Diabetes Mellitus: A review of current trends. Oman Medical Journal, 2012;24(7):269-73.

15. World Health Organization. Diabetes action now: an intiative of the World Health Organization and International Diabetes Federation. WHO publication. 2004:4.

16. Oshodi YO, Adeyemi JD, Aina OF, Suleiman TF, Erinfolami AR. Burden and psychological effects, caregiver experiences in a psychiatric outpatient unit in Lagos, Nigeria. African Journal of Psychiatry, 2012;15:99-106.

DOI: http://dx.doi.org/10.4314/ejhs.v29i6.6 
17. Issa BA, Baiyewu O. Quality of life of patients with diabetes mellitus in a Nigerian teaching hospital. Hongkong Journal of Psychiatry, 2006;16:27-33.

18. Treif PM, Ploutz-Synder R, Dee K, Britton BA, Weinstock RS. The relationship between marital quality and adherence to diabetic care regimen. Annals of Behavioural Medicine, 2004;27(3):148-54.

19. Kwara state of Nigeria. About Kwara state [Internet]. 2017 [cited 2017 February 9]. Available from: https://kwarastate.gov.ng/about-kwara-state.

20. American Diabetes Association. Classification and diagnosis of diabetes. Diabetes Care, 2015;38:S8-S16.

21. Araoye MO. Sample Size Determination. In: Research Methodology with Statistics for Health and Social Sciences. Araoye MO Ed. Ilorin: Nathadex Publishers: 2004:115-120.

22. International Diabetes Federation (IDF) Diabetes Atlas - 7th edition. (accessed on Feb 3, 2015) Available from: www. idf.org/e-atlas.

23. Meyvis T, Van Osselaer SMJ. Increasing the Power of Your Study by Increasing the Effect Size. Journal of Consumer Research, 2018;44(5):1157-1173.

24. Zarit SH, Reeves KE, Bach-Peterson J. Relatives of impaired elderly: correlates of feelingsof burden. Gerontologist 1980;20(6):649-55.

25. Chou K, Chu H, Tseng C, Lu R. The measurement of caregiver burden. Journal of Medical Sciences, 2003;23(2):73-82.

26. Adeosun II. Correlates of caregiver burden amongst family members of patients with schizophrenia in Lagos, Nigeria. Schizophrenia research and treatment, 2013; ID 353809, http://dx.doi.org/10.1155/2013/353809.

27. Stagg B and Larner AJ. Zarit Burden Interview: pragmatic study in a dedicated cognitive function clinic. Progress in Neurology and Psychiatry, 2015;4:23-27.

28. Goldberg DP, Williams P. A User's Guide to the General Health Questionnaire. Windsor: NFER-NELSON; 1988. p24.

29. Goldberg D, Gater R, Sartorius N, Ustun TB, Piccineli M, Gureje O, Rutter C. The validity of two versions of the general health questionnaire( GHQ) in the WHO study of Mental illness in general health care. Psychological Medicine, 1997;27(1):191-7.

30. Abiodun OA. Validity study of the Hospital Anxiety and Depression Scale in general hospital units and community sample in Nigeria. The British Journal of Psychiatry 1994;165(5):669-72.

31. Human D, Fluss SS. The World Medical Association's Declaration of Helsinki. Historical and Contemporary Perspectives. Accessed 2016 July 28. Available from: http://www.wma.net/en/30publications/10poli cies/b3/17c.pdf.

32. Nabuurs-Franssen MH, Huijberts MS, Kruseman AN, Willems J, Schaper NC. Health-related quality of life of diabetic foot ulcer patients and their caregivers. Diabetologia. 2005;48(9):1906-10.

33. Awadalla AW, Ohaeri J, Alwadi SA, Adel MT. Diabetes melitus patients' family caregivers' subjective quality of life. Journal of National Medical Association, 2006;98(5):727-36.

34. Canam C, Acorn S. Quality of life for family caregivers of people with chronic health problems. Rehabilitation Nursing, 1999;24(5):192-200.

35. Anaforoglu I, Ramazanogullari I, Algun E, Kutanis R. Depression, Anxiety and Quality of life of Family Caregivers of patients with Type 2 Diabetes Mellitus. Medical Principles Practice 2012;21:360-5. 
36. Impett EA, Gable SL, Peplau LA. Giving up and giving in: the costs and benefits of daily sacrifice in intimate relationships. J Pers Soc Psychol, 2005;89(3):327-44.

37. Langa KM, Sandeep V, Hayward RA, Chernew ME, Blaum CS, Kabeto DR et al.
Informal Caregiving for Diabetes and Diabetic Complications Among Elderly Americans. Journal of Gerontology, 2002;57(3):177-86.

DOI: http://dx.doi.org/10.4314/ejhs.v29i6.6 